\title{
Variation of sperm parameters after metabolic and antioxidant supplementation in infertility patients with Oligoasthenoteratospermia (Sperm parameters and antioxidants)
}

\author{
Riadh Ben Temime*, Anne Claude Fahrni, Attila Louis Major and Anis Feki \\ Department of obstetrics and gynaecology and reproductive medicine, Fribourg cantonal hospital, Switzerland
}

\begin{abstract}
Background: The World Health Organization estimates that infertility concerns nearly 190 million people worldwide. Male associated factors are found up to $50 \%$ of the cases. This study aimed to investigate the effects of vitamin and antioxidant supplementation on semen parameters and pregnancy rates.

Methods: We report a prospective study comparing sperm parameters before and after micronutrient treatment in 52 infertile male patients. The duration of the study was 15 months. The primary outcomes were the evolution of sperm parameters after treatment intake. The secondary outcomes were pregnancy rates. Wilcoxon Signed Rank test was used for statistical analysis.

Results: The mean age was 36.2 years. Primary Infertility was reported in 35 cases (71.1\%). Varicocele was reported in 12 patients (23\%). Infertility remained idiopathic in 18 cases (34.6\%). Before treatment, the mean sperm concentration was $39.310^{6} / \mathrm{ml}(0.35-290)$. The mean progressive motility was $34.3 \%$ (3-76\%). The mean typical morphology was 3.6\% (1-17\%). After treatment, the mean sperm concentration was $39.610^{6} / \mathrm{ml}(1.4-240)$; the mean progressive motility was $36.2 \%$ (7$78 \%)$; the mean typical morphology was 3.5\% (1-13\%). The main variations of the semen observed after treatment were an improvement of the sperm concentration in $55.8 \%$ and of the progressive motility in $51.9 \%$. Sixteen pregnancies (30.7\%) were obtained. Five pregnancies (9.6\%) were spontaneous and 11 (21.1\%) occurred after assisted reproductive techniques (3 after IVF-ICSI and 8 after intra uterine insemination).
\end{abstract}

Conclusion: The results of this study are in favour of the positive effects of nutraceuticals and antioxidants on semen parameters and pregnancy rates.

\section{Introduction}

The World Health Organization (WHO) estimates that infertility concerns nearly 190 million people worldwide [1]. Nearly one couple over five will consult for infertility. Male associated factors are found up to $50 \%$ of the cases [2]. The WHO reports that sperm concentrations have declined by $57 \%$ worldwide. The causes of male infertility remain idiopathic in almost $40 \%$ to $60 \%$ of these patients [3]. Vitamin and antioxidant supplementation have been proposed as a therapy for oxidative stress-induced sperm abnormalities by reducing protein and DNA damage and apoptosis. We evaluated the effects of a therapeutic formulation (Proxeed Plus ${ }^{*}$ ) on sperm parameters in male infertile patients with oligoasthenoteratozoospermia.

\section{Materials and Methods}

\section{Patients and study characteristics}

We report a prospective observational study comparing sperm parameters before and after micronutrients treatment in infertile male patients between 23 and 60 years having a history of infertility for more than 12 months. Semen samples were collected after 3-5 days of sexual abstinence. The sperm concentration, semen volume, total sperm count, total and progressive motility, typical sperm morphology and vitality variations were analysed before and after 3 months of supplementation with micronutrients containing vitamin and antioxidant therapy (Proxeed Plus from Alfasigma Schweiz AG: consisted of $1000 \mathrm{mg} \mathrm{L}$-carnitine, $500 \mathrm{mg}$ acetyl L-carnitine and other micronutrients: $1000 \mathrm{mg}$ Fructose, $50 \mathrm{mg}$ citric acid, $20 \mathrm{mg}$ CoQ10, 90 mg vitamin $\mathrm{C}, 10 \mathrm{mg}$ zinc, $200 \mu \mathrm{g}$ folic acid, $1.5 \mu \mathrm{g}$ vitamin $\mathrm{B} 12$, and $50 \mu \mathrm{g}$ Selenium).The research project was carried out in accordance to the essentials of good epidemiological practice issued by Public Health Schweiz. All the data were extracted from medical files with respect to the privacy and the dignity of the patients. Each patient was identified by a unique code. The inclusion criteria were defined as having at least one abnormal semen parameter according to WHO 2010 criteria [4] and having taken at least two months of vitamin and antioxidant supplementation. The duration of the study was 15 months from June 2018 to September 2019. The Primary outcomes were the evolution of main sperm parameters according to WHO 2010

*Correspondence to: Riadh Ben Temime, MD. Department of obstetrics, gynaecology and reproductive medicine. Fribourg cantonal hospital. Chemin des pensionnats 2-6, 1708 Fribourg, Switzerland, Tel: 0041779612432 ; Fax: 0041263062901 ; E-mail: Riadh.Bentemime@h-fr.ch

Key words: Male infertility, L-carnitine, oligoasthenoteratozoospermia, sperm parameters, antioxidant

Received: December 01, 2020; Accepted: December 14, 2020; Published: December 17, 2020 
Temime RB (2020) Variation of sperm parameters after metabolic and antioxidant supplementation in infertility patients with Oligoasthenoteratospermia (Sperm parameters and antioxidants)

criteria (concentration, motility, typical morphology and vitality) after treatment intake. The secondary outcomes were pregnancy rates.

\section{Statistical analyses}

Statistical analysis was performed using SPSS IBM. We used a Wilcoxon Rank-Signed test for matched simples to evaluate if the treatment improved the sperm parameters. A two-sided p-value less than 0.05 was considered statistically significant.

\section{Ethical approval}

This study was approved by the Vaud cantonal committee of ethics and research on human beings (Registration number: 2017-01170).

\section{Results}

Fifty two male patients consulting for infertility and having an abnormal spermogram were recruited in the study. All our patients had a micronutrient supplementation (L-carnitine, acetyl L-carnitine and other micronutrients for 3 months. The mean age was 36.2 years ( 23 - 60 years). Infertility of the couple was primary in 35 cases $(71.1 \%)$ and secondary in 17 cases (32.6\%). Two patients (3.8\%) have already conceived with another partner. The mean body weight was 80.9 $\mathrm{kg}(52-125 \mathrm{~kg})$. The mean body mass index (BMI) was 25.9 (17.1 - 45.3), and $17.3 \%$ of the patients were obese (BMI>30). The main medical history was represented by diabetes in 4 cases $(7.6 \%)$ and asthma in 3 cases (5.7\%). The main surgical history was represented by appendicitis in 4 cases (7.6\%), a herniated disc in 2 cases (3.8\%), and an hemithyroidectomy in 1 case (1.9\%).

A history of orchitis was reported in 4 cases (7.6\%), with 1 case of mumps. A history of varicocele was reported in 10 cases (19.2\%), and 4 patients had surgery. A history of testicular cancer was reported for one patient (1.9\%) who had unilateral orchidectomy and chemotherapy. The profession of the patients was manual in 31 cases (59.6\%) and intellectual in 21 cases (40.4\%). Exposition to heat, vehicle driving and toxic products were reported respectively for $2(3.8 \%), 6(11.5 \%)$ and 8 cases $(15.3 \%)$. All patients were tested for hepatitis B and C, syphilis and HIV. Serologies were normal in 50 cases $(96.2 \%)$ and showed hepatitis B in 2 cases (3.8\%). Tobacco and alcohol consumption was reported in $9(17.3 \%)$ and 35 cases $(67.3 \%)$ respectively. A history of drug consumption was reported in 3 cases (5.7\%). Associated sexual dysfunction was reported for one patient (1.9\%). The patients' characteristics and their main medical and surgical history are reported in Table 1.

No female associated infertility factors were reported for 30 patients (57.7\%). In 22 cases (42.3\%), the female partner had associated infertility factors: endometriosis in 6 cases $(11.5 \%)$, a polycystic ovarian syndrome in 5 cases $(9.6 \%)$, pelvic inflammatory disease in 2 cases (3.8\%), vaginal infection in 2 cases $(3.8 \%)$, dysthyroidism in 2 cases (3.8\%), a bicornuate uterus in 1 case (1.9\%), a history of myomectomy in 2 cases $(3.8 \%)$, a unilateral salpingectomy in 1 case $(1.9 \%)$ and a unilateral oophorectomy in 1 case $(1.9 \%)$.

Before treatment, the mean sperm concentration was $39.310^{6} / \mathrm{ml}$ (0.35-290); 19 patients (36.5\%) had an abnormal sperm concentration $\left(<1510^{6} / \mathrm{ml}\right)$. The mean progressive motility was $34.3 \%$ (3-76\%); 29 patients $(55.7 \%)$ had an abnormal progressive motility $(<32 \%)$. The mean typical morphology was $3.6 \%(1-17 \%) ; 34$ patients $(65.3 \%)$ had an abnormal typical sperm morphology $(<4 \%)$. The mean number of extracted spermatozoids after sperm preparation was $18.310^{6}$. The analysis of sperm parameters is reported in Table 2.
Table 1. Patients' characteristics

\begin{tabular}{|l|c|c|}
\hline Characteristics & Median & (Min - Max) \\
\hline Age $($ years $)$ & 36.2 & $23-60$ \\
\hline Weight $(\mathrm{kg})$ & 80.9 & $52-125$ \\
\hline Height $(\mathrm{cm})$ & 176.9 & $160-188$ \\
\hline BMI $\left(\mathrm{kg} / \mathrm{m}^{2}\right)$ & 25.9 & $17.1-45.3$ \\
\hline History & $\mathbf{N}$ & $\mathbf{\%}$ \\
\hline Primary infertility of the couple & 35 & 71.1 \\
\hline Secondary infertility of the couple & 17 & 32.6 \\
\hline Anterior conception (another partner) & 2 & 3.8 \\
\hline Female associated infertility factors & 22 & 42.3 \\
\hline History of orchitis & 4 & 7.6 \\
\hline Prostatitis & 1 & 1.9 \\
\hline Varicocele & 12 & 23 \\
\hline Testicular trauma & 3 & 5.7 \\
\hline Unilateral orchidectomy & 1 & 1.9 \\
\hline Toxic substances exposition & 8 & 15.3 \\
\hline Inguinal hernia surgery & 5 & 9.6 \\
\hline Cryptorchidism & 1 & 1.9 \\
\hline Sexual dysfunction & 1 & 1.9 \\
\hline
\end{tabular}

Table 2. Sperm parameters before and after supplementation treatment

\begin{tabular}{|l|l|l|l|}
\hline Sperm parameter & $\begin{array}{l}\text { Before treatment } \\
(\text { mean)/ (Max-Min) }\end{array}$ & $\begin{array}{l}\text { After treatment } \\
(\text { mean)/ (Max-Min) }\end{array}$ & P-value \\
\hline $\begin{array}{l}\text { Sperm concentration } \\
\left(10^{6} / \mathrm{ml}\right)\end{array}$ & $39.3(0.35-290)$ & $39.6(1.4-240)$ & 0.05 \\
\hline Total sperm count $\left(10^{6)}\right.$ & $117.7(4.2-580)$ & $99.1(3.6-423)$ & 0.850 \\
\hline Volume of ejaculate (ml) & $3.3(1-10.5)$ & $3.4(0.3-8)$ & 0.868 \\
\hline Progressive motility (\%) & $34.3(3-76)$ & $36.2(7-78)$ & 0.547 \\
\hline Total motility (\%) & $40.4(7-80)$ & $41.9(10-82)$ & 0.212 \\
\hline $\begin{array}{l}\text { Typical sperm } \\
\text { morphology (\%) }\end{array}$ & $3.6(1-17)$ & $3.5(1-13)$ & 0.710 \\
\hline Vitality (\%) & $69.8(26-96)$ & $72(19-89)$ & 0.485 \\
\hline pH & $7.43(7.2-7.8)$ & $7.48(7-8)$ & 1 \\
\hline Normal acrosine (\%) & $84.1(65-97)$ & $84.4(58.97)$ & N/A \\
\hline Normal tubuline (\%) & $81.3(29-98)$ & $81(61.96)$ & N/A \\
\hline $\begin{array}{l}\text { Extracted spermatozoids } \\
\text { after sperm preparation } 10^{6}\end{array}$ & $18.3(0.1-218)$ & $14.1(0.1-130)$ & N/A \\
\hline
\end{tabular}

N/A : not applicable

Patients were investigated according to the European Association of Urology guidelines on male infertility [5]. A spermoculture was performed in 41 cases (78.8\%); it was negative in 30 cases and showed an asymptomatic infection in 11 cases (3 Escherichia coli, 2 Staphylococcus aureus, 2 Streptococcus B, 2 Actinomycetes, 1 Ureaplasma urealyticum, 1 Enterobacter). Antibiotics were prescribed in addition to micronutrient treatment. Anti-sperm autoantibodies were detected in 1 case (1.9\%). A urological evaluation with a scrotal ultrasound study was performed in 15 cases $(28.8 \%)$. Two additional new cases of varicocele were discovered by scrotal ultrasound (Total: 12 cases). An additional varicocele cure was indicated in 1 case. Scrotal ultrasound showed a single testicle in 1 patient who had unilateral orchidectomy for testicular cancer. In case of severe semen anomalies (mainly a sperm concentration less than $510^{6} / \mathrm{ml}$ ), a karyotype, testing for Y microdeletions and CFTR gene mutation were performed in 7 cases (13.4\%). All karyotypes were normal, and no Y microdeletion was detected. CFTR gene mutation testing showed a 5T-TG12 polymorphism in 1 case (1.9\%). Genetic counseling was proposed. FSH and testosterone blood level analysis were performed in 6 cases and were all normal. Infertility of the couple remained idiopathic in 18 cases (34.6\%). 
Temime RB (2020) Variation of sperm parameters after metabolic and antioxidant supplementation in infertility patients with Oligoasthenoteratospermia (Sperm parameters and antioxidants)

After treatment, the mean sperm concentration was $39.610^{6} / \mathrm{ml}$ (1.4-240); the mean progressive motility was $36.2 \%$ (7-78\%); the mean typical morphology was $3.5 \%$ (1-13\%). The mean number of extracted spermatozoids after sperm preparation was $14.110^{6}$ (Table 2). The main variations of the semen observed after treatment were an improvement of the sperm concentration in $55.8 \%$ and of the progressive motility in $51.9 \%$. The normalisation of these two parameters was observed in $23 \%$ and $22.1 \%$ of participants, respectively. Although no significant difference was demonstrated by the Wilcoxon Rank Signed Test, there is a trend towards improved sperm concentration and progressive motility (Figure 1A and 1B). The variation of main sperm parameters after treatment is reported in Table 3, and the cumulative percentages histogram is reported in Figure 2.

We also studied the variation of semen parameters after micronutrient supplementation according to some frequent male infertility causes: varicocele (12 patients with five who underwent surgery), semen infection (11 patients who were treated with antibiotics in addition to supplementation), and idiopathic infertility. The results are shown in Table 4. The micronutrient supplementation was more effective for idiopathic infertility. In this situation, the improvement also concerned the semen concentration $(61.1 \%)$ and the progressive motility (50\%) rather than the typical morphology or vitality.
After supplementation treatment, 28 couples (53.8\%) underwent assisted reproductive techniques: intrauterine insemination in 22 cases $(42.3 \%)$ and IVF-ICSI in 6 cases (11.5\%). Other couples preferred either guided intercourse after ovarian stimulation in 3 cases (5.8\%) or expectation with spontaneous intercourse in 21 cases (40.4\%). Sixteen pregnancies $(30.7 \%)$ were obtained after treatment. Five pregnancies (9.6\%) were spontaneous, and $11(21.1 \%)$ occurred after assisted reproductive techniques ( 3 after IVF-ICSI and eight after intrauterine insemination).

Finally, the adverse events were rare after treatment intake; only one case of a gastrointestinal upset was reported (1.9\%).

\section{Discussion}

Infertility affects an estimated $15 \%$ of couples globally. Male fertility issues are major contributors to infertility in couples, accounting for approximately $50 \%$ of these cases [2]. The causes of male infertility remain unknown, and are ambiguous in almost $40 \%$ of these patients [3]. Cessation of smoking, a normal body weight, limited alcohol consumption and a normal exercise pattern are recommended to improve semen quality.

Recent studies have indicated the important role of nutrients, vitamins and minerals in sperm health [6-9]. These micronutrients improve seminal fluid conditions, provide energy to male germ cells

Table 3. Variation of main sperm parameters after treatment

\begin{tabular}{|l|c|c|c|}
\hline Sperm parameter & $\begin{array}{c}\text { Improvement } \\
\mathrm{N}(\%)\end{array}$ & $\begin{array}{c}\text { Stagnation } \\
\mathrm{N}(\%)\end{array}$ & $\begin{array}{c}\text { Deterioration } \\
\text { N (\%) }\end{array}$ \\
\hline Concentration & $29(55.8)$ & $6(11.5)$ & $17(32.7)$ \\
\hline Volume & $25(48 \%)$ & $13(25 \%)$ & $14(27 \%)$ \\
\hline Progressive motility & $27(51.9 \%)$ & $7(13.5 \%)$ & $12(23 \%)$ \\
\hline Typical morphology & $12(23 \%)$ & $34(65.4 \%)$ & $1(1.9 \%)$ \\
\hline Vitality & $16(30.8 \%)$ & $26(50 \%)$ & $6(11.5 \%)$ \\
\hline
\end{tabular}

*Normalisation: A part of the improvement group where the value before treatment was pathological, whereas the value after treatment was normal according to WHO criteria.

Table 4. Variation of sperm parameters after treatment according to aetiology

\begin{tabular}{|c|c|c|c|c|c|c|c|c|c|}
\hline & \multicolumn{3}{|c|}{ Varicocele $(\mathrm{N}=12)$} & \multicolumn{3}{|c|}{ Infection $(\mathrm{N}=11)$} & \multicolumn{3}{|c|}{ Idiopathic infertility $(\mathrm{N}=18)$} \\
\hline & I (\%) & S (\%) & D (\%) & I (\%) & S (\%) & D $(\%)$ & I ( $\%)$ & S (\%) & D (\%) \\
\hline Concentration & 33.3 & 16.7 & 50 & 45.4 & 9.1 & 45.4 & 61.1 & 16.7 & 22.2 \\
\hline Progressive motiliy & 33.3 & 0 & 66.7 & 45.4 & 18.2 & 36.4 & 50 & 11.1 & 38.9 \\
\hline Typical morphology & 8.3 & 83.4 & 8.3 & 27.2 & 54.6 & 18.2 & 22.2 & 55.6 & 22.2 \\
\hline Vitality & 25 & 50 & 25 & 27.2 & 27.2 & 45.5 & 33.3 & 50 & 16.7 \\
\hline
\end{tabular}

I: improvement, S: stagnation, D: deterioration
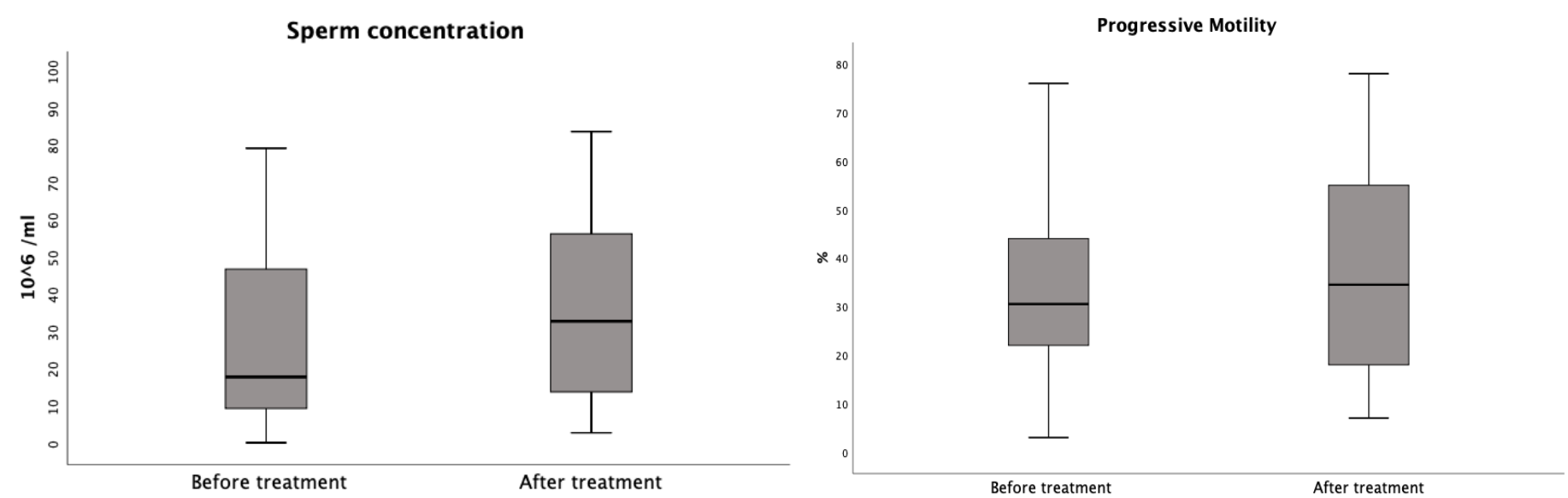

Figure 1. Statistical analysis of the variation of sperm concentration (A) and progressive motility (B) using Wilcoxon Rank Signed Test 
Temime RB (2020) Variation of sperm parameters after metabolic and antioxidant supplementation in infertility patients with Oligoasthenoteratospermia (Sperm parameters and antioxidants)

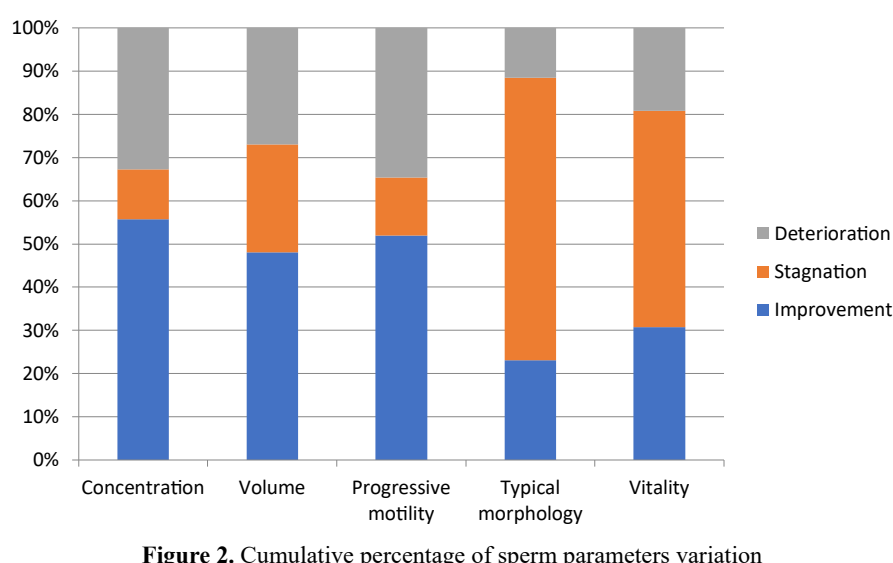

and protect these cells from oxidative stress. Since spermatogenesis is an energy intensive process, it requires a highly balanced supply of minerals, antioxidants and nutrients. Micic, et al. [7] reported sperm volume, progressive motility and vitality significantly $(p<$ 0.001) improved after six months of micronutrient supplementation compared to baseline. Sperm DNA fragmentation index significantly decreased compared to baseline $(p<0.001)$ and the 3-month therapy $(p=0.014)$ in treated men. Busetto, et al. [8] conducted a randomised, double-blind, placebo-controlled trial that investigated the effect of six months of supplementation with l-carnitine, acetyl-l-carnitine and other micronutrients on sperm quality in 104 subjects with oligo- and/ or astheno- and/or teratozoospermia with or without varicocele. Sperm concentration was significantly increased in supplemented patients compared to the placebo $(\mathrm{p}=.0186)$. Total sperm count also increased significantly $(\mathrm{p}=.0117)$ in the supplemented group as compared to the placebo group. Both, progressive and total motility were higher in supplemented patients ( $\mathrm{p}=.0088$ and $\mathrm{p}=.0120$, respectively).

Imamovik Kumalik, et al. [9] reviewed the literature on clinical trials from 2000 to 2013 studying the effects of various types of antioxidant supplements on sperm parameters and pregnancy rates in subfertile males with idiopathic oligoasthenoteratozoospermia (OAT). The majority of the studies confirmed a beneficial effect of antioxidants on at least one of the semen parameters; the biggest effect was determined on sperm motility ( 20 out of 32 studies). In many of these trials, combinations of more antioxidants were assessed. Most commonly studied antioxidants were vitamin E, vitamin C, selenium, CoQ10, N-acetyl-cysteine, L-carnitine and zinc and their favourable effect was confirmed. On the other hand, some clinical trials in this review showed no significant improvement of semen morphology [1012] or no response to treatment in $36.6 \%$ of the cases with Selenium and vitamin E [13] or even reported an adverse effect such as an increase of sperm decondensation with vitamins $\mathrm{C}$ and $\mathrm{E}, \mathrm{B}$-carotene, zinc, and selenium [14].

Another recent metaanalysis was reported by Al Ahmar [15] who reviewed randomized controlled studies published from 2002 to 2017 on the impact of oral antioxidants (vitamin C, vitamin E, L-carnitine, coenzyme Q10, zinc, selenium and pentoxifylline) on seminal fluid parameters in men with idiopathic OAT. Most of the studies reported improvements in at least one semen parameter [15]. The most noteworthy effect was increased sperm motility and concentration when multiple antioxidants were used. Nonetheless, there was a lack of agreement on the dose, the duration of treatment, and whether individual or combined oral antioxidants should be used. The results of our series are consistent with this literature data $[8,9,15-17]$ showing an improvement of the sperm concentration and the progressive motility. Whereas, no significant improvement of typical morphology or vitality was observed.

Different studies also evaluated the effects of supplementation treatment in case of subgroups of infertile patients such as those with varicocele or semen infection [8,18-21]. In our series, the micronutrient supplementation was more effective for idiopathic infertility rather than for varicocele or infection. However, our findings are not significant because of the limited number of patients in each subgroup. Numerous reports have shown that antioxidant supplementation is beneficial for patients with varicocele where oxidative stress is expected to be a factor contributing to the spermatozoa deficiencies. Kizilay, et al. [18] evaluated the effect of oral antioxidant treatment on semen parameters and pregnancy rates in 90 infertile men who underwent varicocelectomy. The improvement in total sperm count $(+45.9 \%$ vs $+26.8 \%)$, sperm concentration $(+71.4 \%$ vs $+54.5 \%)$, sperm count in normal morphology $(+75.7 \%$ vs $+39.9 \%)$, and total $(+28.6 \%$ vs $+18.3 \%)$ and progressive motile sperm count $(+60.4 \%$ vs $+38.9 \%)$ were significantly higher in the treated group than in the untreated group ( $\mathrm{p}=0.011, \mathrm{p}<0.001, \mathrm{p}=0.008, \mathrm{p}<0.001, \mathrm{p}=0.024$ and $\mathrm{p}<0.001$, respectively). A similar study was reported by Gadimov, et al. [19] who investigated the efficacy and safety of a complex of acetyl-L-carnitine, L-carnitine fumarate and lipoic acid for adjuvant antioxidant therapy after microsurgical varicocelectomy (MVE) in 114 men with varicocele and assessed its impact on the level of DNA fragmentation in sperm cells. MVE led to a $21.7 \%$ increase in the progressive sperm motility compared to the baseline level. In patients receiving micronutrient supplementation, this was by $76.7 \%$ at three months. MVE with concurrent micronutrient supplementation resulted in a $22.3 \%$ decrease in the level of sperm DNA fragmentation at three months.

Vicari, et al. [21] evaluated the effects of antioxidant treatment (carnitine and acetyl carnitine) in 54 infertile patients with abacterial prostato-vesiculo-epididymitis (PVE) with normal or abnormal seminal white blood cell concentrations. The authors concluded that carnitines were an effective treatment only in patients with abacterial PVE when seminal white blood cells concentration was normal $\left(<1 \times 10^{6} / \mathrm{ml}\right)$. In this group of patients, the improvement concerned the progressive motility and the viability. The lower efficacy of carnitine treatment in PVE patients with persistently elevated seminal WBC concentrations has suggested that a different anti-inflammatory/antioxidant strategy should be explored in this subgroup of patients.

In addition to DNA fragmentation, other markers of semen quality were evaluated such as acrosin or tubulin formation and reactive oxygen species measurement $[22,23]$. Acrosome reaction and tail movements are essential for fertilisation. Therefore, to ensure the normal function of the spermatozoa, all the acrosome enzymes and tail proteins such as Acrosin (AC), tubulin (TU), dynein (DY), and actin (ACT) have to be present. Hoshi, et al. [24] showed that in cases in which semen showed lower concentration, the fluorescence scores of these proteins were all significantly lower than those of normozoospermia. In cases in which semen showed low motility, the scores of TU, and ACT were significantly less. In semen that contained numerous morphologically abnormal spermatozoa, TU and ACT exhibited a significant reduction. The normality of these fluorescence scores showed a good correlation with pregnancy rate. In our study, the level of semen normal acrosin (normal $>50 \%$ ) and tubulin (normal $>70 \%$ ) were analysed. Eight patients had abnormal acrosin or tubulin semen levels. An improvement was observed in three patients after supplementation. 
Temime RB (2020) Variation of sperm parameters after metabolic and antioxidant supplementation in infertility patients with Oligoasthenoteratospermia (Sperm parameters and antioxidants)

Reactive oxygen species (ROS) can cause sperm DNA damage and integrity of sperm DNA can be measured with DNA fragmentation. Dietary antioxidants may be beneficial in reducing sperm DNA damage, particularly, in men with high levels of DNA fragmentation $[25,26]$. In the metaanalysis of Imamovic Kumalik [9], 5 out of 32 studies confirmed that the usage of different antioxidants had an essential influence on DNA fragmentation and chromatin integrity. Agarwal, et al. [22] reported a multicenter evaluation of the oxidation-reduction potential (ORP) with a dedicated device called MiOXSYS. The authors assessed whether ORP levels could distinguish semen samples that fall within 2010 WHO normal reference values from those that do not. Semen samples were collected from 2092 patients in 9 countries. ORP was negatively correlated with all semen parameters $(\mathrm{P}<0.01)$ except volume. The ORP cut-off value $\left(1.34 \mathrm{mV} / 10^{6} \mathrm{sperm} / \mathrm{ml}\right)$ was able to differentiate specimens with abnormal semen parameters with $98.1 \%$ sensitivity and $40.6 \%$ specificity. Agarwal, et al. [27] proposed then the term Male Oxidative Stress Infertility, or MOSI, as a novel descriptor for infertile men with abnormal semen characteristics, including many patients who were previously classified as having idiopathic male infertility. Elevated ROS levels in the semen may be an etiologic factor for male infertility. It is estimated that $25 \%$ of infertile men have high levels of semen ROS, whereas fertile men do not [27].

Concerning pregnancy rates, a Cochrane review of 48 randomised controlled trials (RCT) reported that men with poor semen quality showed improvement in sperm parameters following antioxidant therapy (28) and found that live birth rate was higher in couples randomised to treatment (OR 4.21; 95\% CI 2.08-8.51) [28]. This review was recently updated by Smits, et al. [6] who included 61 studies with a total population of 6264 subfertile men, aged between 18 and 65 years. They compared and combined 18 different oral antioxidants. The authors concluded that antioxidants might lead to increased live birth rates (OR $1.79,95 \% \mathrm{CI} 1.20$ to $2.67, \mathrm{P}=0.005)$. The clinical pregnancy rate in the treated group was significantly higher than that in the non treated group $(29 \%$ vs $17.9 \%)(p=0.029)$. Results suggested that if the baseline chance of live birth following placebo or no treatment is assumed to be $12 \%$, the chance following the use of antioxidants is estimated to be between $14 \%$ and $26 \%$. However, the evidence was of 'low' to 'very low' quality. In the metaanalysis of Imamovic Kumalik [9], CoQ10, clomiphene citrate with vitamin E, L-carnitine with vitamin $\mathrm{E}$, and selenium with vitamin $\mathrm{E}$ significantly improved spontaneous pregnancy rates during treatment. Greco, et al. [26] confirmed higher pregnancy rates after two months of therapy with $1 \mathrm{~g}$ of vitamin $\mathrm{C}$ and $1 \mathrm{~g}$ of vitamin E daily. After ICSI, the clinical pregnancy rate was $48.2 \%$ after therapy versus $6.9 \%$ before therapy. 12 pregnancies were obtained in the series of Busetto, et al. [8], ten were reported in the supplementation group out of 52 patients (19.2\%). However, in the metaanalysis of Omar, et al. [29] that included 61 studies, the authors identified several medical and nutritional treatments, such as pentoxifylline, coenzyme Q10 and L-carnitine that appeared to improve semen parameters. However, there were limited data suggesting improvements in pregnancy and live birth rates.

Finally, concerning the adverse events of the micronutrient treatment, the metaanalysis of Smits, et al. [6], showed that antioxidants might lead to an increase in mild gastrointestinal upsets when compared to placebo or no treatment (OR 2.51, 95\% CI 1.25 to $5.03, \mathrm{P}=0.010$ ). The risk of gastrointestinal upsets following antioxidant treatment was assumed to be between $2 \%$ and $9 \%$. In our series, only one case of a gastrointestinal upset was reported (1.9\%). Other adverse events, were reported in the review of $\mathrm{KO}$, et al. [30] such as fatigue, malodorous body secretions, headache, loss of appetite, facial flushing. Nausea, headache and vertigo were also reported in the series of Busetto, et al. [8], but were evaluated as not serious and no action was taken.

\section{Conclusion}

The results of this study are consistent with the review of the literature, suggesting the positive effects of nutraceuticals and antioxidants on semen parameters and pregnancy rates. The main variations of semen observed after treatment were an improvement of the sperm concentration and the progressive motility. The pregnancy rate was satisfactory. These results suggest that antioxidants play an essential role in protecting semen from ROS and can improve basic sperm parameters and may be efficacious when included in strategies to improve fertility. Nonetheless, the review of the literature reveals a lack of agreement on the composition, the dose, the duration of treatment, and whether it should only be prescribed to selected patients.

\section{Acknowledgments}

AML conceived the study. RBT collected data and wrote the paper. ACF performed the statistical analysis. AF reviewed literature. Study funding: This research study was supported by a grant provided by Alfasigma Schweiz AG company.

\section{Conflict of interest}

The authors disclose that Alfasigma Schweiz AG company provided a grant to support this research article.

\section{References}

1. Rutstein SO, Shah IH, ORC Macro,WHO (2004) Infecundity, infertility, and childlessness in developing countries. World Health Organization, Calverton.

2. Agarwal A, Mulgund A, Hamada A, Chyatte MR (2015) A unique view on male infertility around the globe. Reprod Biol Endocrinol 13: 37. [Crossref]

3. Gabrielsen JS, Tanrikut C (2016) Chronic exposures and male infertility: the impacts of environment, diet and drug use on spermatogenesis. Andrology 4: 648-61. [Crossref]

4. WHO (2010) WHO Laboratory Manual for the Examination and Processing of Human Semen, World Health Organization, Geneva, Switzerland.

5. Jungwirth A, Diemer T, Kopa Z, Krausz C, Minhas S, et al. (2018) European association of urology guidelines on male infertility.

6. Smits RM, Mackenzie-Proctor R, Yazdani A, Stankiewicz MT, Jordan V, et al. (2019) Antioxidants for male subfertility. Cochrane Database Syst Rev 3: CD007411. [Crossref]

7. Micic S, Lalic N, Djordjevic D (2019) Double blind randomized placebo controlled trial on the effect of L-carnitine and 1- acetylcarnitine on sperm parameters in men with idiopathic oligo-astheno-zoospermia. Andrologia 51: e13267. [Crossref]

8. Busetto GM, Agarwal A, Virmani A (2018) Effect of metabolic and antioxidan supplementation on sperm parameters in oligo-astheno-teratozoospermia with and without varicocele: A double-blind placebo-controlled study. Andrologia 50: e12927. [Crossref]

9. Imamovic Kumalic S, Pinter B (2014) Review of clinical trials on effects of oral antioxidants on basic semen and other parameters in idiopathic oligoasthenoteratozoospermia. Biomed Res Int 2014: 42695. [Crossref]

10. Wirleitner B, Vanderzwalmen P, Stecher A (2012) Dietary supplementation of antioxidants improves semen quality of IVF patients in terms of motility, sperm count and nuclear vacuolization. Int J Vitam Nutr Res 82: 391-398. [Crossref]

11. Busetto GM, Koverech A, Messano M, Antonini G, De Berardinis E, et al. (2012) Prospective open-label study on the efficacy and tolerability of a combination of nutritional supplements in primary infertile patients with idiopathic astenoteratozoospermia. Arch Ital Urol Androl 84: 137-40. [Crossref]

12. Balercia G, Mosca F, Mantero F (2004) Coenzyme Q10 supplementation in infertile men with idiopathic asthenozoospermia: an open, uncontrolled pilot study. Fertil Steril 81: 93-98. [Crossref] 
Temime RB (2020) Variation of sperm parameters after metabolic and antioxidant supplementation in infertility patients with Oligoasthenoteratospermia (Sperm parameters and antioxidants)

13. Moselmi MK, Tavanbakhsh S (2011) Selenium-vitamin E supplementation in infertile men: effects on semen parameters and pregnancy rate. Int J Gen Med 4: 99-104. [Crossref]

14. Menezo YJ, Hazout A, Panteix G (2007) Antioxidants to reduce sperm DNA fragmentation: an unexpected adverse effect. Reprod BioMed Online 14: 418-421. [Crossref]

15. Al Ahmar AT (2018) The effects of oral antioxidants on the semen of men with idiopathic oligoasthenoteratozoospermia. Clin Exp Reprod Med 45: 57-66. [Crossref]

16. Safarinejad MR, Safarinnejad S, Shafiei N, Safarinejad S (2012) Effects of the reduced form of coenzyme Q10 (ubiquinol) on semen parameters in men with idiopathic infertility: a double-blind, placebo controlled, randomized study. J Urol 188: 526-531. [Crossref]

17. Lenzi A, Sgro P, Salacone P, Paoli D, Gilio B, et al. (2004) A placebo-controlled double-blind randomized trial of the use of combined 1-carnitine and l-acetyl-carnitine treatment in men with asthenozoospermia. Fertil Steril 81: 1578-1584. [Crossref]

18. Kizilay F, Altay B (2019) Evaluation of the effects of antioxidant treatment on sperm parameters and pregnancy rates in infertile patients after varicocelectomy: a randomized controlled trial. Int J Impot $R$ 31: 424-431. [Crossref]

19. Gamidov SI, Ovchinnikov RI, Popova AY, Avakyan AY, Sukhikh GT (2017) Adjuvant antioxidant therapy in varicocele infertility. Urologiia 2: 64-72. [Crossref]

20. Chen YW, Niu YH, Wang DQ, Li H, Pokhrel G, et al. (2018) Effect of adjuvant drug therapy after varicocelectomy on fertility outcome in males with varicocele-associated infertility: systematic review and metaanalysis. Andrologia 50: e13070. [Crossref]

21. Vicari E, Calogero A (2001) Effects of treatment with carnitines in infertile patients with prostato-vesiculo-epididymitis. Hum Reprod 16: 2338-2342. [Crossref]
22. Agarwal A, Panner Selvam M, Arafa M (2019) Multicenter evaluation of oxidationreduction potential by MiOXSYS in males with abnormal semen. Asian J Androl 21: 1-5. [Crossref]

23. Homa ST, Vessey W, Perez Miranda A, Riyait T, Agarwal A (2015) Reactive Oxygen Species (ROS) in human semen: determination of a reference range. J Assist Genet 32 757-764. [Crossref]

24. Hoshi K, Sugano T, Yoshimatsu N, Yanagida K (1995) Correlation of Semen Characteristics with Acrosin, Hyaluronidase, Tubulin, Dynein, and Actin of Spermatozoa. Arch Androl 35: 165-172. [Crossref]

25. Zini A, San Gabriel M, Baazeem A (2009) Antioxidants and sperm DNA damage: a clinical perspective. J Assist Reprod Genet 26: 427-432. [Crossref]

26. Greco E, Romano S, Iacobelli M (2005) ICSI in cases of sperm DNA damage: beneficial effect of oral antioxidant treatment. Hum Reprod 20: 2590-2594. [Crossref]

27. Agarwal A, Parekh N, Panner Selvam M (2019) Male Oxidative stress infertility. Proposed terminology and clinical practice guidelines for management of idiopathic male infertility. World J Men Health 37: 296-312. [Crossref]

28. Showell MG, Mackenzie-Proctor R, Brown J, Yazdani A, Stankiewicz MT, et al (2014) Antioxidants for male subfertility. Cochrane Database Syst Rev 12: CD007411. [Crossref]

29. Omar MI, Pal RP, Kelly BD (2019) Benefits of Empiric Nutritional and Medical Therapy for Semen Parameters and Pregnancy and Live Birth Rates in Couples with Idiopathic Infertility: A Systematic Review and Metaanalysis. Eur Urol 75(4):615-625. [Crossref]

30. Ko EY, Sabanegh ES (2014) The role of nutraceuticals in male fertility. Urol Clin North Am 41: 181-193. [Crossref]

Copyright: (C2020 Temime RB. This is an open-access article distributed under the terms of the Creative Commons Attribution License, which permits unrestricted use, distribution, and reproduction in any medium, provided the original author and source are credited. 